\title{
Altered Polyamine Metabolism in Cystic Fibrosis
}

\author{
DIANE HADDOCK RUSSELL, MICHAEL G. ROSENBLUM, ROBERT C. BECKERMAN, BRIAN G. M \\ DURIE, LYNN M. TAUSSIG, AND DON R. BARNETT

\begin{abstract}
Department of Pharmacology, Division of Respiratory Sciences and Pediatric Pulmonary Section, Department of Pediatrics, and Division of Hematology and Onocology, University of Arizona Health Sciences Center, Tucson, Arizona and Department of Human Biological Chemistry and Genetics, University of Texas Medical Branch,
\end{abstract} \\ Galveston, Texas, USA.
}

\begin{abstract}
Summary
Children with cystic fibrosis excreted elevated urinary levels of all three polyamines-putrescine, spermidine, and spermine. Heterozygote parents excreted intermediate concentrations of the polyamines, but not levels significantly different from levels in normal controls. Patients with cystic fibrosis who were administered a tracer amount of $\left[{ }^{14} \mathrm{C} \mid\right.$ spermidine excreted $11-13 \%$ of the radiolabel within $72 \mathrm{hr}$ whereas normal controls excreted 60-76\% of the radiolabel within $72 \mathrm{hr}$. Spermine excretion was positively correlated with increased pathology as assessed by the National Institutes of Health (NIH) clinical score, whereas urinary putrescine and spermidine levels were negatively correlated with increased pathology.
\end{abstract}

\section{Speculation}

It seems that urinary polyamine levels may be used both as nonspecific biochemical markers of clinical disease and as prognostic indicators in cystic fibrosis patients.

Cystic fibrosis is an autosomal recessive genetic disease present mainly in Caucasian populations. The major manifestations, pancreatic dysfunction and chronic pulmonary disease, are associated with mechanical obstruction of organ ducts by abnormally viscous mucus secretions $(1,5,6)$. DiSant'Agnese et al. (4) provided evidence that increased mucus secretion was a result of abnormalities in all exocrine glands. Numerous studies have uncovered a variety of biochemical abnormalities in patients with cystic fibrosis, but neither the basic biochemical defect nor the pathogenic mechanisms of the disease have been elucidated. Cystic fibrosis patients have been found to have an abnormally high $\mathrm{NaCl}$ content in their sweat. A test based on chloride sweat levels, however, is not predictive of disease severity (18). More recently, a ciliary inhibitory factor has been described in the serum of homozygous patients and some obligate heterozygotes. This cytotoxic substance, when added to the ciliary systems of oyster gill or rabbit trachea, results in an alteration or cessation of normal ciliary activity $(2,16)$. The cilia test has been useful as a developmental tool and has allowed for the partial purification of the ciliary inhibitory factor.

Several laboratories have reported altered polyamine levels in whole blood samples from patients with cystic fibrosis $(3,8,10)$ In a recent study, Cohen et al. (3) analyzed various blood components to assess precisely which cells had altered polyamine concentrations. The spermidine concentration in erythrocytes of patients with cystic fibrosis was markedly elevated (150\% of controls). Further, there were marked decreases in the spermine concentration in both lymphocytes and granulocytes. Thus, whole blood samples from cystic fibrosis patients had an elevated spermidine/spermine ratio. Although these observations are of interest, it is well documented that intracellular polyamine concentra- tions can be altered in a variety of ways in both normal and pathologic tissues $(13,15)$. Rosenblum et al. (11) reported that patients with cystic fibrosis did not conjugate or excrete $\left[{ }^{14} \mathrm{C}\right]$ spermidine as rapidly or extensively as normals or patients with cancer (12).

In this report, the authors studied the relation of extracellular polyamine metabolism to the expressed pathology of cystic fibrosis. It was found that children with cystic fibrosis excreted elevated urinary levels of all three polyamines-putrescine, spermidine, and spermine. Heterozygote parents excreted intermediate concentrations of the polyamines, but not levels significantly different from levels in normal controls. Patients with cystic fibrosis who were administered a tracer amount of $\left[{ }^{14} \mathrm{C}\right]$ spermidine excreted $11-13 \%$ of the radiolabel within $72 \mathrm{hr}$ whereas normal controls excreted $60-76 \%$ of the radiolabel within $72 \mathrm{hr}$. Spermine excretion was positively correlated with increased pathology as assessed by the NIH clinical score, whereas urinary putrescine and spermidine levels were negatively correlated with increased pathology.

\section{MATERIALS AND METHODS}

\section{MATERIALS}

$\left[{ }^{14} \mathrm{C}\right]$ Spermidine $(12.5 \mathrm{mCi} / \mathrm{mm})$ was obtained from New England Nuclear, Boston, MA. Hank's solution, butterfly needles, and heparin were obtained from Abbott Laboratories, Chicago, IL.

\section{METHODS}

Urinary samples were collected from patients positively diagnosed as cystic fibrosis homozygotes (four males, three females, age range 5-11 yr, mean age 8 ), from their obligate heterozygote parents (five males, three females, age range $26-38$ yr, mean age 30) (no evidence of disease), and from two groups of age-matched controls: heterozygote age-matched normal group (three males, three females, age range $20-27 \mathrm{yr}$, mean age 26 ) and cystic fibrosis age-matched normal group (four males, one female, age range 5$8 \mathrm{yr}$, mean age 7). Urine of age-matched children with asthma and lung disease also was analyzed. Urine was acidified with concentrated $\mathrm{HCl}$ and kept frozen until analysis. Polyamine concentrations in hydrolyzed urine samples were assayed on a Durrum D-500 amino acid analyzer as previously described (17). Collections were 24 -hr or 8 -hr specimens. It was found that serial 8-hr or 24-hr urines from the same patient show remarkably consistent values for polyamine concentration when the excretion of the polyamine is expressed per mg of creatinine. When this normalizing technique is not used, values can be 2- to 3-fold different from day to day. It must be assumed that these fluctuations, when no reference is used, are due to improper collections or changes in kidney function, or both $(7,14)$.

$\left[{ }^{14} \mathrm{C}\right]$ Spermidine $(10 \mu \mathrm{Ci})$ was added to $1 \mathrm{ml}$ of sterile Hank's solution containing $1 \%$ human serum albumin and the $\mathrm{pH}$ adjusted to 7.2 with sterile $\mathrm{NaOH}$. Butterfly needles were inserted 
into both the left and right forearm veins. The iv lines were flushed with sterile $0.9 \% \mathrm{NaCl}$ containing heparin (10\%). One venous line was used exclusively for blood sampling after injection of the radioisotope through the opposite line. Venous blood samples (3 $\mathrm{ml}$ ) were withdrawn at various times after injection (up to $60 \mathrm{~min}$ ) and placed in 3-ml heparin Vacutainer tubes. These tubes were spun at $2000 \mathrm{rpm}$ for $10 \mathrm{~min}$ and the plasma was decanted. Each plasma sample was assayed in duplicate for ${ }^{14} \mathrm{C}$ by counting a $100-$ $\mu l$ sample in $10 \mathrm{ml}$ Aquasol. The total urine output for $72 \mathrm{hr}$ postinjection was collected in urine containers, acidified with concentrated $\mathrm{HCl}$ to prevent bacterial growth, and refrigerated. The total urine volumes were measured and a $100-\mu 1$ aliquot of each sample was counted for ${ }^{14} \mathrm{C}$ activity in $10 \mathrm{ml}$ Aquasol.

$\left[{ }^{14} \mathrm{C}\right]$ Spermidine metabolism was studied in a group of six normal volunteers (four males, two females, age range 25-29 yr, mean age 26) and two cystic fibrosis patients (one male, age 23 and one female, age 26). All studies were approved by the Human Subjects Committee, University of Arizona, and informed, written consent was obtained before each study.

A group of patients with cystic fibrosis (five males, seven females, age range 4-23 yr, mean age 11) was examined and assigned a prognostic clinical score on the basis of several clinical tests and a physical examination (19). A urine specimen collected at the time of the evaluation was acidified and kept frozen until analysis. Polyamine content was analyzed as previously described All of the patients with cystic fibrosis who were assigned an $\mathrm{NIH}$ clinical score as well as having urinary specimens evaluated for polyamine levels were receiving daily multivitamin therapy, sudafed ( $30 \mathrm{mg}$ four times a day), Accelerase and cotazyme before meals, and all received antibiotics based upon results of culture sensitivities. Most were receiving dicloxacillin $(250 \mathrm{mg}$ four times a day) or Bactrin (trimethoprim and sulfamethoxazole, $80 \mathrm{mg}$ and $400 \mathrm{mg}$, respectively, four times a day).

\section{RESULTS}

URINARY EXCRETION OF POLYAMINES IN CYSTIC FIBROSIS PATIENTS, HETEROZYGOTE PARENTS, AND NORMALS

Urinary polyamine levels in patients with cystic fibrosis, their obligate heterozygote parents, and age-matched controls for both groups are shown in Table 1 . In comparison to normals and heterozygotes, the cystic fibrosis patients had urinary levels of all three polyamines that were 2 - to 10 -fold higher. Elevations of putrescine, spermidine, and spermine in urine of children with cystic fibrosis were statistically significant $(P<0.0001)$ compared to both the heterozygote parents and to normal children. They were higher, also, than in the urine of children with other lung disorders (Table 1). In heterozygotes, no significant differences from controls were found in urine levels of putrescine $(P<0.55)$ or spermidine $(P<0.25)$; however, a slight elevation $(P<0.011)$ in spermine level in the urine of heterozygote parents was noted compared to age-matched controls.

\section{$\left[{ }^{14} \mathrm{C}\right]$ SPERMIDINE METABOLISM IN NORMALS AND CYSTIC FIBROSIS} PATIENTS

Plasma decay curves for $\left[{ }^{14} \mathrm{C}\right]$ spermidine in normal and cystic fibrosis patients are plotted in Figure 1 . At $1 \mathrm{~min}$ after $\left[{ }^{14} \mathrm{C}\right]-$

Table 1. Urinary polyamines in patients with cystic fibrosis, in obligate heterozygotes, in patients with other lung diseases, and in agematched normal volunteers

\begin{tabular}{|c|c|c|c|c|c|}
\hline \multirow[b]{2}{*}{ Mean values } & \multirow[b]{2}{*}{ Male/Female } & \multirow[b]{2}{*}{ Mean age } & \multicolumn{3}{|c|}{ Urinary Polyamines ( $\mu \mathrm{g} / \mathrm{mg}$ creatinine) } \\
\hline & & & Putrescine & Spermidine & Spermine \\
\hline Normals & $3 / 3$ & 25 & $2.73 \pm 0.59$ & $1.56 \pm 0.42$ & $0.06 \pm 0.01$ \\
\hline Heterozygotes & $5 / 3$ & 30 & $3.04 \pm 0.90$ & $1.80 \pm 0.34$ & $0.17 \pm 0.09$ \\
\hline Normals & $4 / 1$ & 7 & $2.09 \pm 0.57$ & $1.79 \pm 0.49$ & $0.14 \pm 0.08$ \\
\hline Asthmatics and severe lung disease & $3 / 2$ & 7 & $2.45 \pm 0.65$ & $2.07 \pm 0.51$ & $0.22 \pm 0.15$ \\
\hline Cystic fibrosis & $4 / 3$ & 8 & $9.80 \pm 1.40^{1}$ & $4.00 \pm 0.45^{1}$ & $1.81 \pm 0.33^{1}$ \\
\hline
\end{tabular}

Cystic fibrosis

Data differ from age-matched normals, heterozygotes, and patients with other lung disorders $(P<0.0001)$.

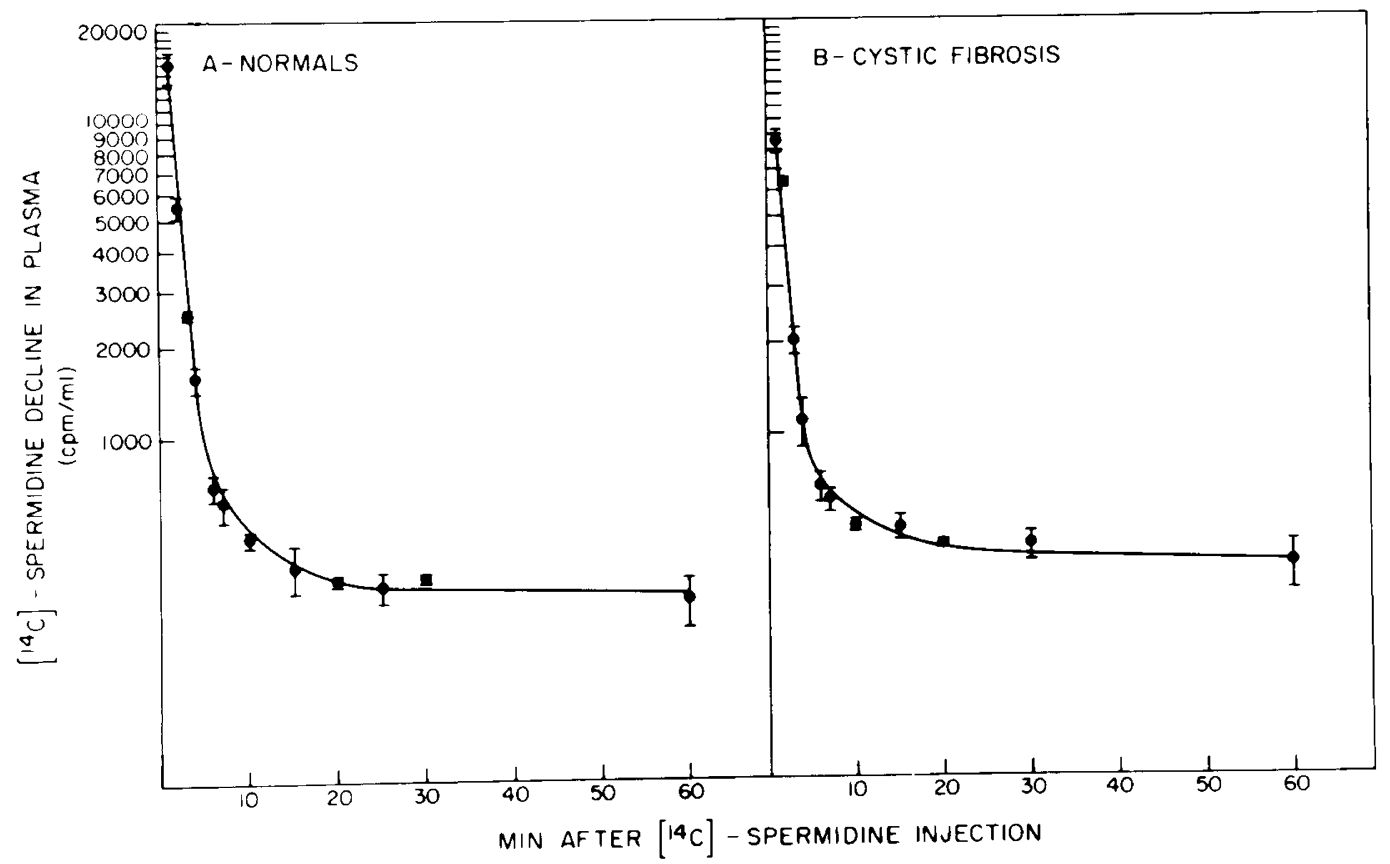

Fig. 1. Decline in plasma radioactivity at various times after $\left[{ }^{14} \mathrm{C}\right]$ spermidine injection $(100 \mu \mathrm{Ci}$, iv) in $(\mathrm{A})$ normal volunteers $(N=6)$ and $(\mathrm{B})$ in patients with cystic fibrosis $(N=2)$ was assessed in a $0.1 \mathrm{ml}$ plasma aliquot by counting in $10 \mathrm{ml}$ Aquasol scintillant. 
spermidine injection, the patients with cystic fibrosis had about $50 \%$ the amount of radiolabel in plasma as compared to controls. This suggests a rapid sequestration of the radiolabel in patients with cystic fibrosis. However, in both groups there was a similar level of radioactivity within $10 \mathrm{~min}$. Urinary excretion of the ${ }^{14} \mathrm{C}$ radiolabel was markedly reduced in cystic fibrosis patients compared to normals (Table 2). Cystic fibrosis patients excreted only $11-13 \%$ of the injected radiolabel within $72 \mathrm{hr}$ as compared to 60 $76 \%$ excreted by normal individuals within the same time period

\section{URINARY POLYAMINE LEVELS AND NIH CLINICAL SCORE}

Correlations between the NIH clinical score and urinary polyamine levels in cystic fibrosis patients are shown in Figure 2. In all 12 patients studied, urinary levels of putrescine, spermidine, and spermine were elevated compared to normal values. However, the urinary level of spermine was positively correlated to extent of disease whereas putrescine and spermidine were negatively correlated to extent of disease. Those patients with advanced clinical disease (NIH score less than $70, N=4$ ) were found to have significantly lower urinary levels of putrescine and spermidine $(P$ $<0.05$ ) than those with less severe disease (NIH score greater than $70, N=8$ ). In contrast, spermine urinary levels were highest in patients with advanced disease (NIH score less than 70 ) and significantly lower $(P<0.01)$ in patients with less severe disease (NIH score greater than 70). The method of least squares was used to determine the best fit line and was plotted by a Wang computer.

\section{DISCUSSION}

Changes in polyamine levels in physiologic fluids have been correlated with alterations in cellular kinetics. In patients with metastatic cancer, the putrescine concentration correlates with the $\left[{ }^{3} \mathrm{H}\right]$ thymidine labeling index of the tumor cells, and the spermidine concentration reflects the cell turnover or cell loss factor of the tumor $(7,14-16)$. In cancer patients, plasma or urine levels of spermidine accurately reflect tumor cell kill in response to chemotherapy $(7,16)$. Elevated extracellular polyamine levels also have been found in other pathologies characterized by abnormal cell growth fractions and cell death components $(9,15)$. There are not other well characterized extracellular markers of cell growth and cell death.

The elevated polyamine excretion observed in patients with cystic fibrosis may be related to destruction of excretory gland cells as the disease progresses $(5,6)$. Further, alterations in urinary levels of polyamines are related to the decreased ability of patients with cystic fibrosis to excrete polyamines. Patients with cystic fibrosis excreted only $11-13 \%$ of a $\left[{ }^{14} \mathrm{C}\right]$ polyamine label in their urine within $72 \mathrm{hr}$ whereas normals and patients with cancer excreted 70-76\% (Table 2).

More surprisingly, patients with cystic fibrosis excreted very high concentrations of spermine compared to normals and patients with cancer (15). Spermine concentrations are higher in highly differentiated tissues such as exocrine glands, and this extracellular increase may be a reflection of the destruction of glandular cells (14, 15). Further, the spermine concentration in the urine is positively correlated with the extent of disease as established by the NIH clinical score. This is in marked contrast to the negative

Table 2. Excretion of $\left[^{14} \mathrm{C}\right]$ spermidine in normals and cystic fibrosis patients

(\% of injected ${ }^{14} \mathrm{C}$ recovered in urine)

\begin{tabular}{cccc} 
Time after injection & & & \\
\cline { 2 - 4 } (hr) & Normals $(N=6)^{\prime}$ & CF patient 1 & CF patient 2 \\
\hline 4 & $22 \pm 2$ & 6.0 & 3.2 \\
10 & $32 \pm 3$ & 7.0 & 4.0 \\
24 & $47 \pm 4$ & 7.9 & 7.0 \\
48 & $65 \pm 7$ & 10.7 & 9.7 \\
72 & $68 \pm 8$ & 13.5 & 11.2 \\
\hline
\end{tabular}

${ }^{1}$ Data are expressed as the mean \pm SEM.
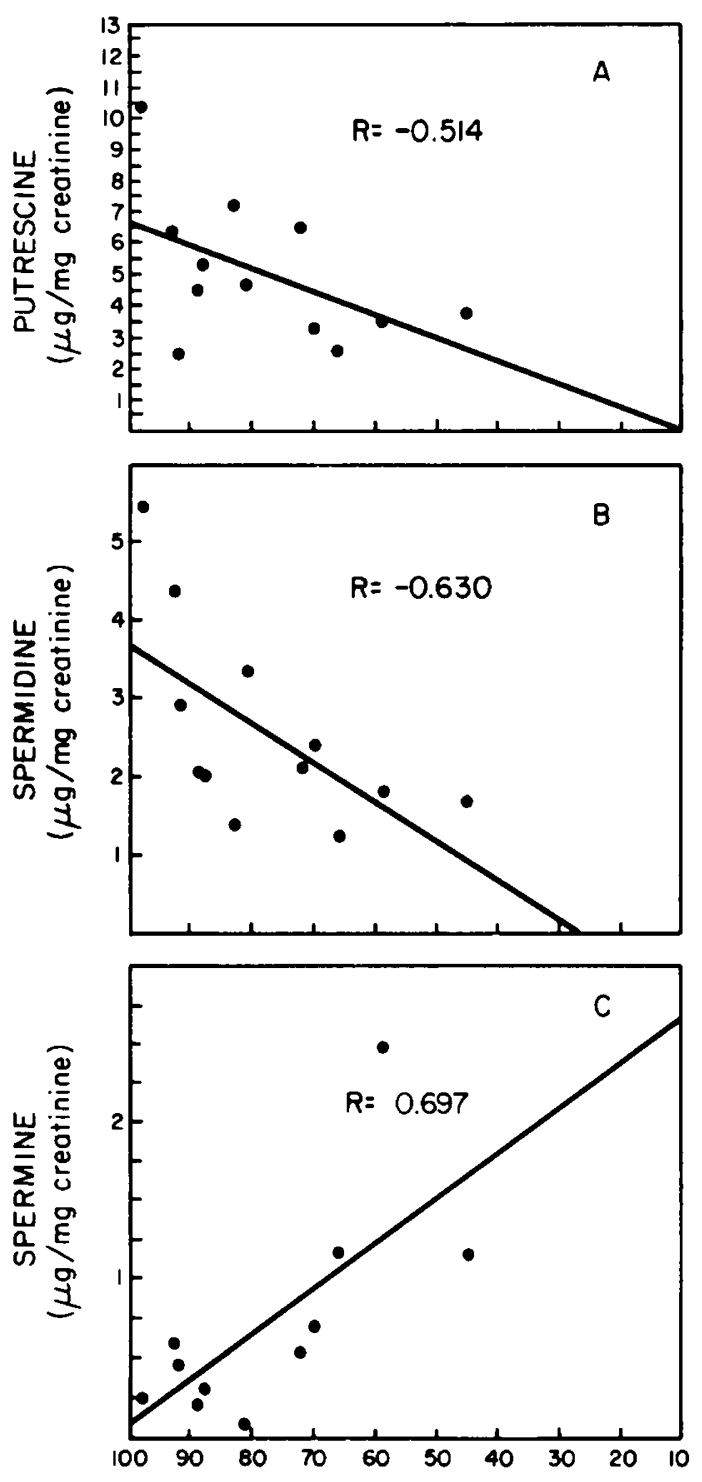

CLINICAL SCORE

Fig. 2. Urinary levels of (A) putrescine, (B) spermidine, and (C) spermine of 12 cystic fibrosis patients as a function of increased pathology as assessed by the NIH clinical score. (See Materials and Methods.)

correlation between the clinical score and the urinary levels of putrescine and spermidine. In our patient population, those cystic fibrosis patients with NIH scores greater than $70(N=8)$ (mild disease) excreted significantly higher levels of all three polyamines than age-matched normals (Table 1). Thus, urinary polyamine levels may be used both as nonspecific biochemical markers of clinical disease and as prognostic indicators in cystic fibrosis patients. Alterations in excretory patterns should precede major changes in extent of pathology and polyamine analysis would, therefore, be more useful and easier than the extensive clinical tests now utilized.

In summary, alterations in extracellular levels of polyamines related to pathologic growth appear quite general. However, urinary polyamine levels may be used as objective biochemical markers of clinical disease in patients with cystic fibrosis. In the case of cystic fibrosis, it will be important to establish the mechanism or mechanisms by which polyamine metabolism is altered as a function of increased pathology.

\section{REFERENCES AND NOTES}

1. Andersen, D. H.: Cystic fibrosis of the pancreas and its relation to celiac disease Amer. J. Dis. Child., 56: 344 (1938). 
2. Bowman, B.. Lockhart, L., and McCombs, M.: Oyster ciliary inhibition by cystic fibrosis factor. Science, 164: 325 (1969).

3. Cohen, L. F.. Lundgren, D. W., and Farrell, P. M.: Distribution of spermidine and spermine in blood from cystic fibrosis patients and control subjects. Blood, 48: 469 (1976).

4. diSant'Agnese, P. A., Darling, R. C., Perera, G. A., and Shea, E.: Abnormal electrolyte composition of sweat in cystic fibrosis of the pancreas. Pediatrics, 12: 549 (1953).

5. diSant'Agnese, P. A., and Davis, P. B.: Research in cystic fibrosis. N. Engl. J. Med., 295: 481 (1976).

6. diSant'Agnese, P. A., and Talamo, R. C.: Pathogenesis and physiopathology of cystic fibrosis of the pancreas. N. Engl. J. Med.. 277: 1287 (1967).

7. Durie, B. G. M., Salmon, S. E., and Russell. D. H.: Polyamines as markers of response and disease activity in cancer chemotherapy. Cancer Res., 37: 214 (1977).

8. Lundgren. D., Farrell, P., and diSant'Agnese. P.: Polyamine alterations in blood of male homozygotes and heterozygotes for cystic fibrosis. Clin. Chim. Acta, 62: 357 (1975).

9. Proctor, M. S., Fletcher, J. V., Jr., Shukla, J. B., and Rennert, O. M.: Elevated spermidine and spermine levels in the blood of psoriasis patients. J. Invest. Dermatol., 65: 409 (1975).

10. Rennert, O., Frias, J., and Lapointe, D.: Methylation of RNA and polyamine metabolism in cystic fibrosis. In: Fundamental Problems of Cystic Fibrosis and Related Diseases, p. 41 (International Book Corporation, New York. 1973).

11. Rosenblum, M. G., Durie, B. G. M., Beckerman, R. C., Taussig, L. M., and Russell. D. H.: Cystic fibrosis: decreased conjugation and excretion of $\left[{ }^{14} \mathrm{C}\right]$ spermidine. Science, 200: 1496 (1978)

12. Rosenblum, M. G. Durie. B. G. M., Salmon, S. E., and Russell, D. H.: Metabolism of $\left[{ }^{14} \mathrm{C}\right]$ spermidine and $\left[{ }^{14} \mathrm{C}\right]$ putrescine in normal volunteers and in cancer patients. Cancer Res., 38: 3161 (1978).

13. Russell, D. H.: Polyamines in growth-normal and neoplastic. In: D. H. Russell: Polyamines in Normal and Neoplastic Growth, p. I (Raven Press, New York, 1973).

14. Russell, D. H.: Clinical relevance of polyamines as biochemical markers of tumor kinetics: a review. Clin. Chem., 23: 22 (1977).

15. Russell, D. H. and Durie, B. G. M.: Polyamines as Biochemical Markers of Normal and Malignant Growth (Raven Press, New York, 1978).

16. Russell, D. H., Durie, B. G. M., and Salmon. S. E.: Polyamines as predictors of success and failure in cancer chemotherapy. Lancet. 2: 797 (1975).

17. Russell, D. H., and Russell, S. D.: Relative usefulness of measuring polyamines in serum. plasma, and urine as biochemical markers of cancer. Clin. Chem., 21: 860 (1975).

18. Spock, A., Heick, H. M. C., Cress, H., and Logan. W. S.: Abnormal serum factor in patients with cystic fibrosis of the pancreas. Pediatr. Res., I: 173 (1967).

19. Taussig, L., Kattwinkel. J., Friedewald, W., and diSant'Agnese. P.: A new prognostic score and clinical evaluation system for cystic fibrosis. J. Pediatr.. 82: 380 (1973).

20. Taussig, L. M., and Landau, L. I.: Cystic fibrosis. In: V. C. Kelley: Practice of Pediatrics, Vol. 4, p. 1 (Harper and Row, New York City, New York. 1976).

21. Dr. Russell is the recipient of a Research Career Development Award CA-00072 from the National Cancer Institute. This study supported, in part, by a grant from the Cystic Fibrosis Foundation.

22. Dr. Beckerman is a Fellow of the American Lung Association.

23. Requests for reprints should be addressed to: Diane H. Russell. Ph.D., Department of Pharmacology, University of Arizona Health Sciences Center. Tucson. AZ 85724 (USA)

24. Received for publication August 21, 1978.

25. Accepted for publication October 24, 1978. 